\title{
Sustainable Development Strategies of the Port Authority: the Network Approach
}

\author{
Marcella De Martino ${ }^{1, a}$ \\ ${ }^{1}$ IRAT-CNR Via G. Sanfelice 8, 80134 Naples, Italy \\ ${ }^{2}$ m.demartino@irat.cnr.it
}

Keywords: Sustainable Development, Port Authority, Relationship Network.

\begin{abstract}
Recent years have witnessed a profound evolution of ports, induced by a wide range of factors, such as: (a) technological developments in shipping, cargo-handling and storage equipment, and information and communication systems; (b) changing patterns of international trade; (c) a broadening complexity of global supply chains; and (d) a changing governance models of the port as a consequence of the process of privatization in Europe. The growing size and complexity of port functions have inspired an ever more interesting and useful scientific debates on the social, economic and environmental effects of these transformations, and, more specifically, on the relationship between the port and the city. The paper addresses, to this end, an emerging managerial perspective in the decision making process of Port Authority: the network. This perspective allows to understand the nature of relationship networks shaping the competitive and cooperative dynamics of the port and to identify the boundaries for an active role of the Port Authority in defining the sustainable development of port within its own territory.
\end{abstract}

\section{Introduction}

Ports are of great economic importance for regions and countries in terms of value added, employment and investments [1]. Besides that, however, ports also provide a unique and important strategic contribution to the international competitiveness of firms in these regions and countries [2,3]. In this respect, international competitive dynamics, economies of scale and globalization have emphasized the key role of technological innovation, port-city integration and knowledge in order for Port Authorities (PA) and port operators to achieve and maintain a competitive advantage [4,5]. However many paradoxes characterize port cities/areas: some conflicts are generated by negative environmental impacts, due to the high level of energy consumption; to air and water pollution, to natural resource consumption. Other conflicts are generated by the effort to preserve the specific cultural landscape and to satisfy the needs of economic development. Innovative approaches are required to mitigate conflicts in these areas, promoting a win - win (synergistic) approach for the smart sustainable development of the port in the city [6]. From the urban planning perspective, Fusco Girard [6] suggests to consider the social economic system ${ }^{1}$ as the engine for sustaining the synergistic smart development model of the port city. From the regional economic perspective, other authors look at ports as geographically localized sources of innovation and regional growth: Hall and Jacobs [7], in particular, emphasize the role played by spatial and non-spatial dimensions of proximity (institutional and social) in influencing the development and diffusion of innovation, while Cahoon et al. [8] point to the crucial importance of specific and regional port's resources to stimulate innovation capabilities and competitiveness of firms and Territories. Coherently to their policy-oriented nature, both contributions assume a key role that the PA can play in favouring the sustainable development of the port and its territory. However, from a managerial perspective, ports represent an ideal case setting for advancing the understanding of the value generation and distribution within complex relationship

\footnotetext{
${ }^{1}$ Social economic system is characterized by value creation processes that are different from conventional economic ones. It is able to increase cultural resilience because it produces, in its exchanges, virtuous circular processes: reciprocity, social responsibility and public spirit. In a word, social economy replaces/regenerates the social capital that makes the economy and democracy work. It stimulates heritage/culture economy and also employment
} 
networks, given their very inter-organizational nature. To this end, the work aims at deepening the contribution of relationship networks to the sustainable development of ports. Relationship network represents a rich field of research for exploring the interactive nature of value creation given the multiple and strong interdependencies among port operators and firms of the regional economic system (hinterland). In more details, it is argued that any port is characterized by different relationship networks (hierarchical, collaborative, spot interactions, etc) as the result of the port operators ability to manage the competitive and cooperative relationships with suppliers and customers, not exclusively located in the port perimeter, but extended to local economic systems. In such networks, value creation is accomplished through different coordination mechanisms in order to mitigate the conflictuality and the divergence of the strategic aims of the actors participating in the port value creation process; value distribution, on the other side, is a consequence of power influence on inter-firm relationships. At PA's policy level, the work promotes a bottom-up perspective aimed at defining policy actions according to what "really" happens within the organizational and managerial context of ports and, more specifically, by taking into account the nature of relationship networks shaping the competitive and cooperative local dynamics. This new perspective of analysis allows to identify the boundaries for an active role of the PA, as facilitating or as a community manager and entrepreneur [9] in the definition of sustainable development strategies. The paper is structured as follows: in the first section, the complexity of the port has been interpreted according to the network perspective that allows to understand the cooperative and competitive relationships between port actors and the other stakeholders of the territory. The second section focuses on PA's policy actions for boosting the development of relationship networks while the last section is dedicated to some initiatives aimed at fostering the culture of innovation in ports.

\section{The conceptualization of port as a network}

A general model based on the concept of the Supply network has been proposed by De Martino and Morvillo [10]. Supply network, in the SCM literature, is "the set of supply chains that describe the flow of goods and services from its original source to its end customer" [12]. This concept considers the companies to be like open systems, influenced by the other actors in the environment in which they operate and dependent on the resources supplied by other organisations; through different forms of interactions the companies can have access to and make use of external resources owned by other network actors. The actors are defined by the activities they carry out and by the resources they control; they are connected to the other network actors through relationships. The identity of an actor is therefore made of the unique combination of resources it owns and the activities it manages In this model, the port is represented as a network of actors that carry out a number of activities, sharing different resources. According to this view, the value for the client is not created by a single company, but it is co-produced in combination with other actors in the network. The greater the degree of interdependence between the network's actors, the more the potential co-produced value [13]. The features of supply chains and the nature of relationships in the network have to be considered in the definition of Port Sustainable Development strategies, as they determine physical and knowledge-based resources that contribute to increase customer satisfaction and, contextually, allow to determine how value is created and distributed in the port -market interactions. Figure 1 provides a simplified view of port network from a managerial perspective, where the landlord Port Authority $^{2}$ has the capacity to conclude contracts (including concession agreements), enforce standards and make rules applicable within the port context. Port operations are carried out by private business operators. In particular, firm A has to export products to D; many port operators are involved in performing activities through different resources: the shipping company SC, the towage, pilotage

\footnotetext{
${ }^{2}$ The ownership structure of port can be represented by four types of models: Public Service Port; Tool Port; Land Lord Port and Fully Privatized Port. Each of these models is characterized by a different power of regulation and administration of the public body, the Port Authority. In this paper, the focus is on the Land Lord Port model, typical ownership structure of the most of the European Ports. Under this model, the Port Authority acts as a regulatory body of port operations.
} 
and mooring operators ( $\mathrm{T}, \mathrm{P}$ and $\mathrm{M})$, the terminal operator $\mathrm{TO}$, the multimodal transport operator MTO and the freight forwarder FF. From the FF's perspective, the main customer is the manufacturing firm A that requires specific services attributes (cost, time, frequency and quality) to export products overseas. FF will be in charge of the logistics and transport chain organization through the involvement of different service providers: MTO for the inland transport, SC for the maritime transport. From the SC's perspective, the main customer will be FF, and service providers will be the terminal operating company (TOC) and pilotage and mooring operators (T, $\mathrm{P}$ and $\mathrm{M}$ ).

In such a network, what drives value co-creation in the service production process? And what is the role of Port Authority in boosting value co-creation? In order to answer to these questions, three ideal types of port service supply chains can be identified with reference to specific targets of port's customers: shipping company $(\alpha)$, multimodal transport operator/freight forwarder $(\beta)$ and shipper/manufacturing firm $(\gamma)$. Each of this supply chain will be characterized by different bundles of resources that can foster value co-creation in the port.

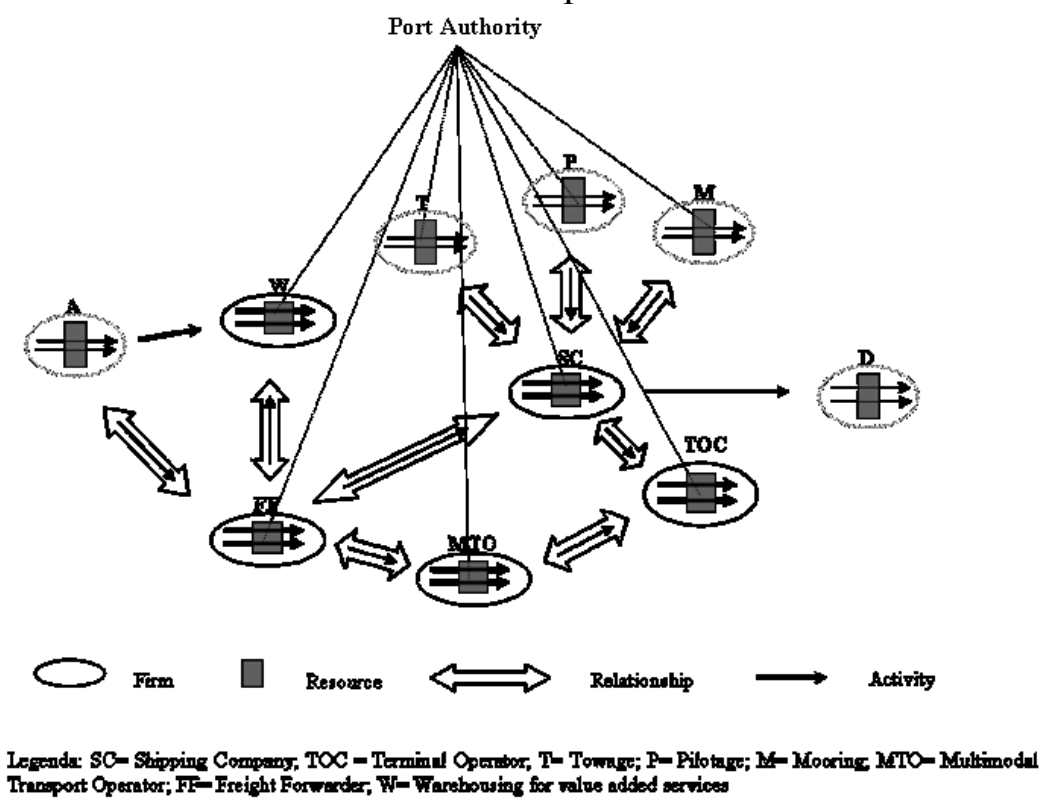

Figure 1: A simplified view of port network [12]

The unit of analysis of value co-creation is the dyad and, extensively, the network. In Figure 2, the traditional dyadic relation is characterized by the interactions between the port service provider (TOC) and the port customer (SC). With reference to port service suppliers (T, M, P operators), pilotage is a mandatory technical-nautical service organized on a monopoly basis in most European ports; whereas towing and mooring services can be provided by either the public or private sector on a voluntary or mandatory basis, exclusively or in competition with other operators. The core service the supply of technical/nautical and terminal services (vessel tie-up services, container/cargo handling and transfers) - is represented by the sphere generated by the matching of the supply and the demand. Physical resources necessary for providing these services are those allocated by the Port Authority such as terminal and quay and those deployed by port operators (assets for the supply of maritime transport and cargo handling). The port shows an approach mainly focused on internal logistics, based on the supply of cargo handling services as the main customer is represented by shipping companies. In this case, strategic options are aimed at maximizing throughput, improving shipping companies' satisfaction and increasing the efficiency of port operations. This is the typical and traditional service supply chain in the port, and know-how and Information and Communication Technology (ICT) systems are well established and available in the market. Current business dynamics witnessed dominant positions of shipping companies and terminal operators in the maritime transport and cargo handling activities; they integrate vertically in the supply chain, in order to increase efficiency and effectiveness of their own business, leaving little rooms for other members in the network to develop 
their own assets and operations. In this situation, value generation is confined in the port perimeter and related to the operational efficiency of the vertically integrated operators.

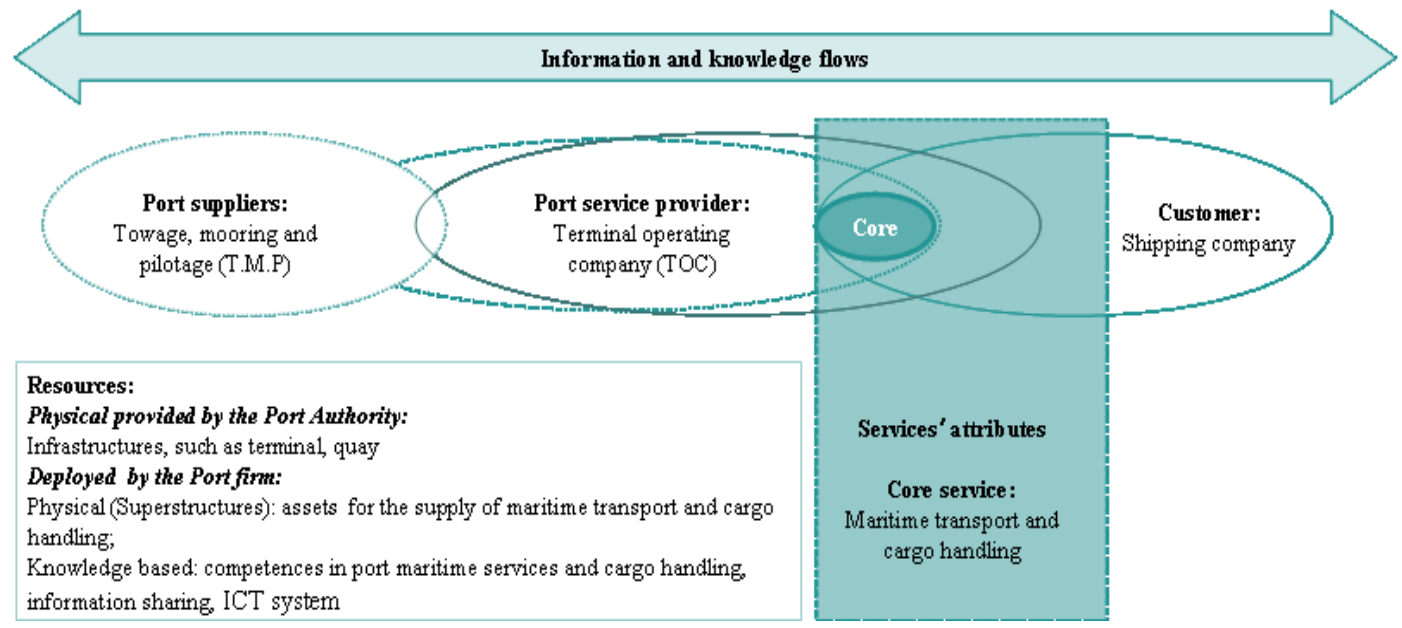

Fig. 2: Port service supply chain $\alpha$ : the core service of the port [13]

In Figure 3, the port expands its core business to include the supply of complementary services (inland transport and warehousing). The bundles of resources necessary for providing intermodal services are the physical resources allocated by the Port Authority that allows the port to be interconnected with the local transport system and the knowledge based one, that can be related to the training and educational services, to the networking activity and technology development. In order to provide intermodal services, different forms of inter-organizational relationships will be developed by port actors for the control and sharing of resources leading to customer's satisfaction, such as the assets for the provision of supplementary services, such as road or railways transport. In particular, the development of new rail connections, while it represents a first strategic objective for the integration of ports with the market (especially in the contestable hinterland), it is however complex and requires substantial investments. Rail operators are reluctant to start new connections unless risks are limited; in this respect, the Port Authority can play a strategic role, by making direct investments in the hinterland or by developing partnerships with the main local railways operators for the acquisition of know-how and competences to guarantee the sustainability of these services.

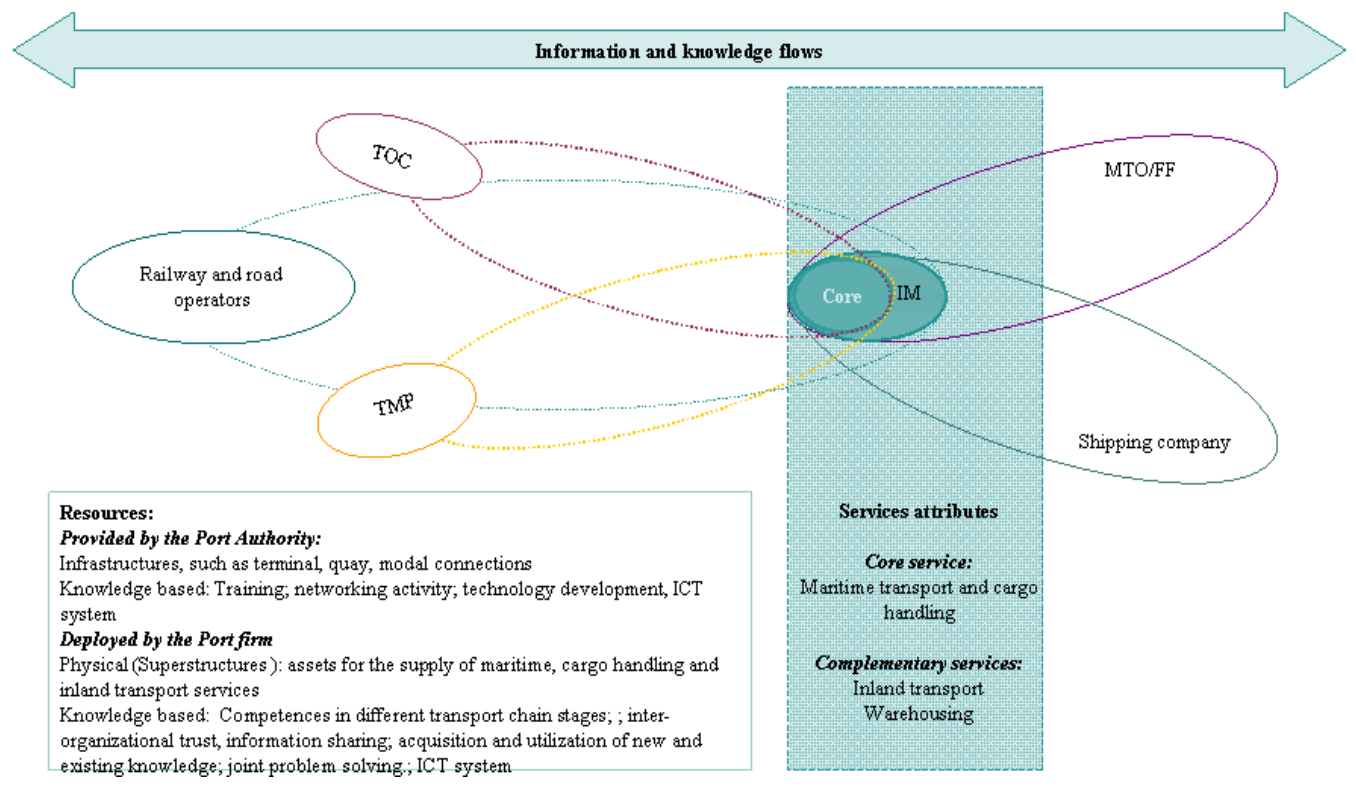

Fig. 3: Port service supply chain $\beta$ : intermodality [13] 
For example, in an increasing number of ports such as Le-Havre, Genoa, Barcelona, Rotterdam, Antwerp, Trieste, the Port Authorities have invested in adequate network of railway and road connections in order to favour the growth of container traffic and overcome the lack of space within the port perimeter. In the port of Le Havre, the shipping companies CMA-CGM and MOL supply intermodal services. CMA-CGM has opted for controlling internally the provision of handling and inland transport services by having capital shares of GMP - the stevedoring company controlling the terminal of France - and of RSC and Rail link (road and rail operators). On the contrary, MOL's supplies intermodal services by contractual relationships with GMP for the handling of containers and by stipulating other contracts with haulers for the distribution of cargoes. These relationship networks determine different value co-creation processes within the firm (the port business operator), the port (the dyad or supply chain) and the territory (the whole network).

Finally, the port can further extend its influence beyond the traditional boundaries towards the hinterland, including activities, resources and actors of the regional economic system (Figure 4). In this case, the Port Authority invests in new physical resources such as logistics area, dry port, distripark and processing area. A great number of interactions develop (or potentially can be developed) among port actors and others firms of regional economic system (shipper/manufacturing firm A), in the process of production of core (maritime transport and handling) and complementary services (inland transport and warehousing; value added logistics, manufacturing and distribution). In this representation, port is the springboard for the economic development of the hinterland and strategic options are oriented to the development of strategic partnerships with inland ports, dry ports.

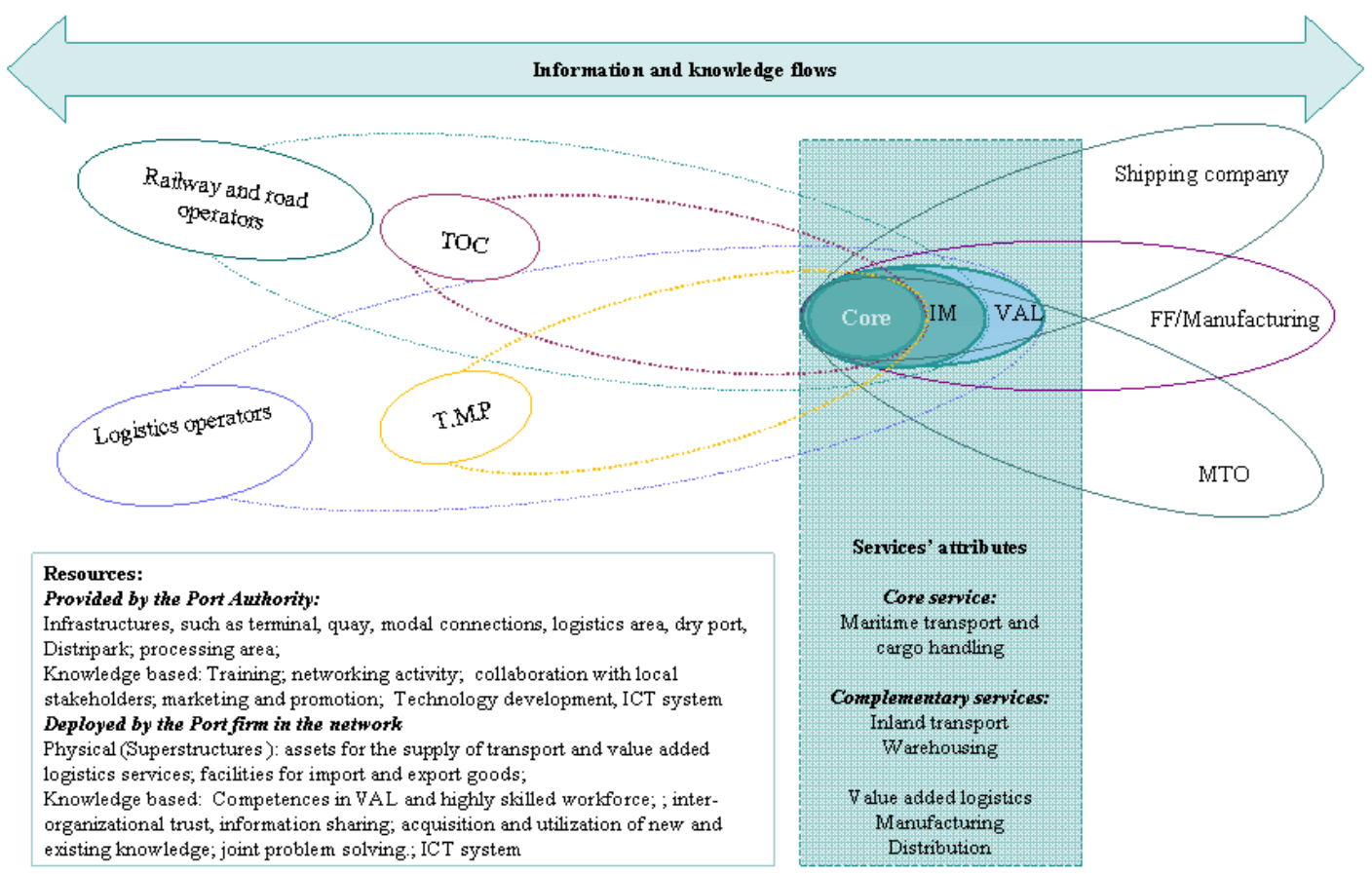

Fig. 4. Port service supply chain $\gamma$ : value added logistics [13]

For example, the Port Authority of Rotterdam established three distriparks in order to provide value-added logistics with comprehensive facilities for distribution operations at a single location, connected directly to container terminals and multimodal transport facilities for transhipment, employing the latest in information and telecommunication technologies. In the same way, the Port Authority of Le Havre created different logistics parks for the supply of a complete range of logistics services, from bulk logistics to optimization of the supply chain. The companies located in the logistics areas are connected to the Port Authority's community information system, accelerating all the procedures for goods transit, in particular those related to Customs formalities. For example, in the port of Le Havre, CMA-CGM supplies also value added logistics services to European retailers (Carrefour and Danone) through a strategic alliance with SDV international logistics. Also in this 
case, different governance models of the service supply chains develop: hierarchical, relational and the last driven by the Port Authority's intervention. Each these networks will lead to different patterns of value distribution: in the single firm, in the dyad, along the supply chain and at network's level. In conclusion, the activation of a process of value generation in the port depends on a set of resources (public and private) that will increasingly integrate the ports with its territory; however, the benefits of these investments could be shared and diffused in the port and in the territory through the development of relationship networks. This conclusion, even more, supports the need to investigate the nature of relationship networks shaping the competitive and cooperative dynamics of the port-market interactions

\section{Port Authority' actions for boosting relationship networks}

With respect to the macro-economic and "aggregated" approach in the port planning process, it is suggested to combine also a market-oriented approach as this can be more effective in defining the actions coherent with the potential role of the port for its market/hinterland. In this regard, port service supply chains can represent potential stages of a development path that Port Authority could follow in order to catch the opportunity offered by its economic and social context. In particular, value creation from port supply chains $\alpha$ to $\gamma$ can be generated, specifically, by: (1) the development of new activities such as intermodality, warehousing, distribution, value added logistics and manufacturing; (2) the involvement of a great number of specialized operators in the field of transport and logistics; and (3) the use and combination of different typologies of resources, especially intangible (information sharing, inter-organizational trust, knowledge acquisition and mobilization) as these are competencies hard to imitate and encourage the development of inter-organizational networks between the port and the regional economic system.

The table 2 shows possible Port Authority's actions in boosting the development of multiple interactions between the port and its territory. In particular, the service supply chains $\beta$ and $\gamma$ identify an increasing number of resources that Port Authority should develop and allocate so that port operators could interact and develop innovative logistics services that expand the port's boundaries towards the regional economic system. The concession of terminal, inland terminal and other logistics resources to port operators is, as highlighted in the previous section, one of the most important tools for Port Authority to affect value creation in the port.

Table 2: Port Authority's policy actions for boosting the development of relationship network [13]

\begin{tabular}{|c|c|c|c|c|}
\hline & Port service supply chain $\alpha$ & Port service supply chain $\beta$ & Port service supply chain $\gamma$ \\
\hline \multirow{3}{*}{$\frac{\mathscr{n}}{\frac{\pi}{x}}$} & $\begin{array}{l}\text { Network } \\
\text { and } \\
\text { Networking }\end{array}$ & $\begin{array}{ll}\circ & \text { Private Public Partnership } \\
\circ & \text { Concession agreement for } \\
\text { terminal management } \\
\text { - } \\
\text { Partnership with other } \\
\text { competing ports }\end{array}$ & $\begin{array}{ll} & \text { Private Public Partnership } \\
\circ & \text { Concession agreement for } \\
\text { inland terminal } \\
\text { management } \\
\circ \\
\text { Partnership with transport } \\
\text { policy makers at local } \\
\text { national and European } \\
\text { levels }\end{array}$ & $\begin{array}{ll}\circ & \text { Private Public Partnership } \\
\circ & \text { Interaction with all local } \\
& \text { stakeholders } \\
\circ & \text { Concession agreement for } \\
& \text { logistics area management }\end{array}$ \\
\hline & Knowledge & - Standardized & $\begin{array}{ll} & \begin{array}{l}\text { Knowledge and } \\
\text { intermodal chain learning }\end{array} \\
\circ & \begin{array}{l}\text { Education and Training } \\
\text { regime }\end{array} \\
\end{array}$ & 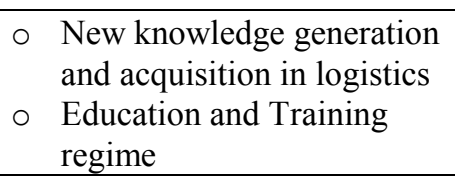 \\
\hline & Technology & $\begin{array}{l}\text { Largely available on the } \\
\text { market }\end{array}$ & $\begin{array}{ll} & \text { Custom informatization } \\
\circ & \text { Devoted to the integration } \\
\text { in the transport chain } \\
\circ & \text { EDI }\end{array}$ & 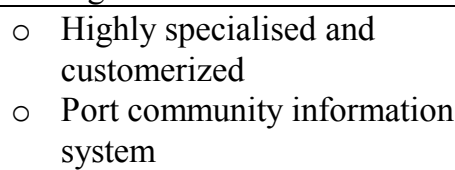 \\
\hline
\end{tabular}


Through concession policy, Port Authority can retain some control of the organization and structure of the supply side of the port market, while optimizing the use of scarce resources such as the land. Shifting from a hierarchical form of governance $(\alpha)$ to a networked governance pivoted by the PA $(\gamma)$, landlord port authorities can embrace concession policy not only as a mean to promote competition between port operators, but also to enhance the collaboration and coordination of port activities through resource allocation and create economical, relational and social connections between the port and the marketplace.

At this regard, Public-Private Partnerships can be used to share the risks associated with huge investments in the hinterland and develop the networks that underpin the innovation process. These partnerships allow the pooling of resources and combination of skills. An appropriate legislative framework needs to be in place to allow the balance between the management of physical resources to the private sector and the sustainability - from the economic, social and environmental perspectives of these resources with respect to various local stakeholders.

The active role of the Port Authority should also be directed to making port actors aware of the existence of a network of interdependencies between the activities they perform and those of the firms of the regional economic system, and hence that the development of collaborative relationships can improve performance and long lasting competitive advantage. Policy formulation and implementation should be the result of intensive communication, close interaction and consensus building among all local Institutions and Government. The Port Authority can play a facilitating role in this respect by stimulating the dialogue and the development of strategic partnerships with inland ports, dry ports and co-operation or "co-opetition" with other, neighboring, ports. Knowledge is progressively being perceived as the core driver of port sustainable development and competitiveness. In port service supply chain $\alpha$, knowledge flows mostly concerns shipping companies' needs and are typically exchanged within the dyadic interaction to improve the quality and efficiency of the services supplied. Shifting to the other two configurations, the variety and complexity of knowledge flows increases in terms of actors involved in the learning processes as well as domains of application. In this regard, the PA can play a crucial role not only in facilitating intermodal learning processes within the port's networks, but also in fostering the generation and exchange of new logistics knowledge. A large variety of port operators in the port, such as cargo handling firms, warehouse operators and transport companies could benefit from the quality standards of education. A suitable training and education program could be determined by a set of collaborative initiatives taken by the relevant actors in the port with the aim of improving the quality and availability of labor. In this respect, education is considered as a public service in many countries and Port Authority and public education institutes can play a major role. The ability of Port Authority to create coalitions that invest in training and education infrastructures is nowadays crucial. Many European Port Authorities are increasingly investing in education and training thorough the development of specific research programs with Universities and Research centers. Just to mention few examples, a number of courses and workshops are directed to strategic issues such as: risk management strategies; freight mobility policy; sustainability strategy; yard management best practices; latest gate technologies; security and safety in the port and in the supply chain. Finally, technology represents a further point of Port Authority's agenda. The Port Community information System (PCS) is an example of technology that has allowed the port to expand its own boundaries toward the hinterland. In this system, generally managed by the Port Authority, each network actor (shipping companies, terminal operating companies, port service providers, maritime agents, MTO, freight forwarders, logistics operators, distributors, retailers and manufacturing firms) shares customised information on inbound and outbound flows, increasing the communication efficiency and effectiveness in the port.

\section{Some initiatives aimed at fostering the culture of innovation and sustainability in ports}

On a managerial level, the framework can generate important implications by fostering, where applied, distributed value creation processes in ports. In fact, when a Port Authority becomes aware of 
the strategic role of inter-organizational relationships as new sources of value creation and competitiveness, it can set a systematic evaluation of their nature and contribute to improve and sustain port's development. The recognition of the interactive nature of relationships among port actors in the port service supply chains represents a critical and fundamental issue for spreading the culture of innovation and sustainability the port, especially from a cultural perspective, as it allows interpretation and consideration of collaboration as a means of value creation. Collaborative spirit and mutual trust are fundamental in order to create reciprocal benefits and a higher level of involvement of the port actors in the network. Only based on a proper understanding of the features and rationale for the formation of relationships between actors of port community and all actors involved in the process of value creation for the final customer, Port Authority can foster new and more effective forms of innovation, especially in $\beta$ and $\gamma$. These networks should be characterized by the development of collaboration among all port actors including manufacturing companies in its own hinterland. It is critical that the Port Authority provides the leadership and vision to coordinate these efforts and promote a culture of innovation and sustainability in the port. Building on a collaborative view of port's inter-organizational networks, many initiatives can be promoted that bring together policy, business, government procurement and research perspectives and resources to generate innovative solutions to existing and future challenges. A culture of innovation and sustainability can be nurtured on a continuing basis by promoting the creation of dedicated innovation networks around specific development challenges of the port service supply chains that involve a cooperative exchange of knowledge, technologies and resources among port operators, industrial partners and technology partners. Among the most critical challenges to be addressed, the EU Innovation 2020 strategy or the Horizon 2020 program define Societal Challenges as one of the main priorities, and address the need to gear the innovation process to societal needs. At this regard, the issue of "responsible innovation" appears to be a future challenge for managers in the port business. The diffusion of responsible innovation initiatives and the dissemination of best practices and paradigm cases within an online port community could be an effective way of fostering responsible innovation processes. Port authorities and relevant companies could publish their responsible research and innovation results in a collective online directory. This initiative could raise the level of trust and support within society and favor a combined effort of port authorities, companies and local stakeholders towards responsible innovation processes. Another way to foster a culture of innovation within the port is the active participation of Port Authorities to European Union funded projects. The objective of these projects is to enhance the participation of the different stakeholders of the port and transport industry and local community, and to define shared and specific actions of implementation of the innovation processes. For example, under the title "Aspects of future port strategies in Europe", the INTERREG IV-C project Port Integration, led by Hamburg Ministry for Economy, Transport and Innovation, brings together port experts from 9 different European countries and Russia to exchange their experiences in European and regional strategies for maritime transport and port strategy. Through exchanging experiences and good practices among the regions, the project aimed at creating a culture of sustainable innovation on specific issues such as "Maritime Transport and Port Interfaces" (PCS) and "Hinterland Transport, Gateways, Dry ports and other innovative logistic concepts". Finally, the recent born of spontaneous and no-profit associations, the so-called "think tank", is a further response of the port and transport communities to the need to promote a shared and sustainable vision of innovation for the future years. The aim of these "think tanks" is to build a common vision on the future challenges envisioned, for example, in the EU development agenda and to propose effective actions for the achievement of the sustainable development's objectives. At this regards, it is very interesting the BTj Think tank, a breeding-ground for the discussion of the TransBaltic Macroregional Transport Action Plan. This think tank, constituted in 2012 by academics, industry operators and institutions, supports the EU in the process of creation of an integrated multimodal transport system around the Baltic by proposing an optimum scenario (path) to achieve in the year 2030 and laying down a number of so called policy actions, instrumental in following this path. 


\section{References}

[1] C. Ferrari, M. Percoco, A. Tedeschi: Ports and local development: evidence from Italy. International Journal of Transport Economics, 37(1), (2010), pp. 9-30

[2] M. E. Porter: The competitive advantage of nations. New York: TFree Press (1990)

[3] F. A. J. Van Den Bosch, R. Hollen, H. W. Volberda, M. G. Baaij: The strategic value of the Port of Rotterdam for the international competitiveness of the Netherlands: a first exploration. Rotterdam: INSCOPE/RSM Erasmus University, ISBN 978-90-817220-2-5, (2011)

[4] H. Haugstetter, S. Cahoon: Strategic intent: guiding port authorities to their new world?. Research in Transportation Economics, 27, (2010) p. 30-36

[5] C-C. Yang, P. B. Marlow, C-S. Lu: Knowledge management enablers in liner shipping. Transportation Research Part E, 45, (2009), p. 893-903

[6] L. Fusco Girard: The urban future, Bollettino del Dipartimento di Conservazione dei Beni Architettonici ed Ambientali, vol.12, (2012), p. 19-33

[7] P.V. Hall, W. Jacobs: Shifting proximitie: the maritime ports sector in an era of global supply chains. Regional Studies 44 (9), (2010), pp. 1103-1115

[8] S. Cahoon, H. Pateman, S-H Chen: Regional port authorities: leading players in innovation networks?, Journal of Transport Geography, Elsevier (2012)

[9] P. Verhoeven: A review of Port Authority functions: towards a renaissance?, IAME Conference (2009), Paper 2-34

[10] M. De Martino, A. Morvillo: Activities, resources and inter-organisational relationships: key factors in the Port competitiveness. Maritime Policy and Management, 35 (6), (2008), pp. $571-589$

[11] H. Hakansson, G. Persson: Supply Chain Management: The Logic of Supply Chains and Networks. International Journal of Logistics Management, 15 (1), (2004), pp.1 -26

[12] R. Lamming, T. Johnsen, J. Zheng, C. Harland: An initial classification of supply networks. International Journal of Operations \& Production Management, 20 (6), (2000), pp. 675-691

[13] M. De Martino, L. Errichiello, A. Marasco and A. Morvillo: Logistics innovation in Ports: an inter-organizational perspective, in Research in Transportation Business \& Management, Volume on Port Performance and Strategy, (2013), pp. 123-133 